\title{
Designing and Modelling of a Low-Cost Wireless Telemetry System for Deep Brain Stimulation Studies
}

\author{
Milner Vithayathil', T. Jarin², S. R. Boselin Prabhu³, Richard Ningthoujam ${ }^{1}$ and \\ Loitongbam Surajkumar Singh ${ }^{1}$ \\ 'National Institute of Technology Manipur, Imphal - 795004, Manipur, India; \\ vithayathilmilner@nitmanipur.ac.in, richard.ningthoujam@gmail.com, surajloi@yahoo.co.in \\ 2Jyothi Engineering College, Thrissur - 679531, Kerala, India; \\ jeroever2000@gmail.com \\ ${ }^{3}$ VSB College of Engineering, Coimbatore - 642109, Tamil Nadu, India; \\ eben4uever@gmail.com
}

\begin{abstract}
Objectives: To design and develop a Wireless device for Deep Brain Stimulation studies in Rat Model. Methods/ Statistical Analysis: In order to model the design, we have used ASIC (Application Specified) and Off the Shelf Components that helps the device Cheap and portable. We have designed the device using Allegro PCB Design and OrCad. Findings: Before the real time execution in rat models, we tested our device in vitro. Device is observed using oscilloscope. We ensured the life time of the device that can extend up to 90 days. In comparing with other commercial stimulators, this device has long duration of life time with high accuracy in delivering output pulses and less expensive. In order to show the reliability, we have included complete schematics and market price of the components used. Application/Improvements: The current device can be made use to deliver Unbalanced Biphasic Output Pulses.
\end{abstract}

Keywords: Pulse Generator, Stimulator, DBS, ICSS

\section{Introduction}

The settled remedial mediations in the neurological and mental area are the electrical incitement in the cerebrum, called by "Deep Brain stimulation (DBS)". This system has created from confirmed clinical studies and specialized developments ${ }^{1}$. Different cerebrum related clutters, for example, Parkinson's malady, dystonia, epilepsy or constant agony can be treated through this Brain Stimulation. The utilization of DBS is broadening to mental signs, for example, over the top enthusiastic clutters, Tourette's disorder, dependence. The human work model of Brain Stimulation framework must be utilized in the wide kind of creatures; this isn't conceivable in little creatures and a noteworthy bottleneck for these most regularly utilized creatures as test ${ }^{2}$.

These models which are utilized for the learning of the pathogenetic instruments and different treatments for human development issue and mental disorders, for example, "OCD, have normally been made by neurotoxins, acting specifically on neurons influenced by human infections" 
In spite of the fact that the adequacy of DBS treatment has been demonstrated clinically, further investigation of the system of cerebrum work direction by profound mind incitement is fundamental. Hence, studies about Brain Stimulation are required.

The incitement range values and the evaluation results need to been additionally explored to deliver a solid and effortlessly well-suited DBS gadget. The current Brain Incitement Device for a human is too much massive for small subjects. Likewise, development of individual DBS gadgets is excessively confounded and expensive that it isn't financially savvy for rodent preliminaries. $\mathrm{In}^{4}$ proposed built up a little size DBS gadget which met the necessities for creature preliminaries. Nonetheless, the incitement beat of their gear was customizable just by eight voltage steps, which does not take care of the clinical demand. The gadget for rodents created by ${ }^{4}$ was using radio waves for power backup still it suffers precision during the real-time experiments since the subject is inclined to move.

Now, instructing of a bio robot is done by invigorating exact cerebrum zones of a creature which should be instructed to execute controlled turns. The problem with the voltage incitement is that both the potential inside the cell and outside the cell will be the same, further it cannot be used for controlling the subjects in due time. Apart from that range values will always be inconsistent because of the capacitive idea of neuron frameworks and the comparable ways of neuronal layer ${ }^{5}$.

It is very essential to know about the influence of Brain Stimulation on subjects in order to trace out the mechanisms of the Brain Circuits. Many strategies are being used to learn and study about the Brain Incitement in which a big number of them used intense stimulations in the brain and another group checked about the long period incitement in the subjects. So the most important task is designing such a stimulator that can be accustom in all the testing environments in terms of size, precision, technology, power and safety ${ }^{6}$.

From all these facts, there is a definite requirement of a small portable stimulator where we can program the parameters for enhancing the study of rodents through DBS. We are aiming most smart microstimulator with an advantage of less power dissipation, the long lasting life of three months, inexpensive ${ }^{\mathrm{z}}$ highly accurate with precision and smallest size as possible.

\subsection{Literature Survey}

50 years back "Deep Brain Stimulation" was first utilized who embedded cathodes in the somatosensory thalamus of patients experiencing differentiation torment. Later on, more average destinations provoked by Reynolds who distributed the primary proof that electrical incitement of the dark issue encompassing the Sylvain conductor could yield sufficient absence of pain to allow stomach activity in rodents. These days for the alleviation of unending obstinate pain coming about because of an assortment of neurotic conditions, Deep Brain Stimulation is an acknowledged clinical procedure. In spite of the expansive number of clinical examinations depicting relief from discomfort by profound cerebrum incitement; a few late surveys of the clinical writing propose that the aftereffects of these systems change impressively among various investigations, that numerous neurosurgeons discover the strategy flighty, that no critical advancement has been made as of late to enhance its viability and dependability, and that extensive difference still exists with respect to issues identified with the method itself $\stackrel{8}{ }$.

In the earlier time, a device located near to cage and the wire was kept over the moving subject's cage before stimulation?. When it requires the stimulation, the user will manually connect to the subject's skull. This method suffers a lot of limitation. The user cannot explore more about behavioural patterns of the subject. Due to the limitation of the span of the cable, it will result in unwanted results.

There are many installed Real-Time frameworks have just been intended for rodents, endeavoring to fulfill recently revealed requirements.

We propose evaluating these arrangements, concentrating on one vital rule: the situation of the circuit in the rat body.

Several examinations have revealed gadgets with embedding an electronic part in the stomach some portion of the subject, associated with a cathode embedded in the brain ${ }^{4,10}$. The huge preferred standpoint is that the 
rodent can move rapidly after the medical procedure. This decision demonstrates significant hazard factors back to back to a medical procedure, similar to diseases, particularly in the mid-region territory. It is an unquestionable requirement to utilize biocompatible materials. In the above examinations, incitement factors are customized through RF joins; Inter-correspondence is modified utilizing mux, and the RF producer is a cylindrical gadget containing the creature all through the programming of incitement. The mobility of the subject is considerably reduced and apart from that, the Brain Stimulation output cannot be completed within the stipulated time. Since the battery is surgically kept inside the subject, it will be a difficult process if the user needs to replace or battery gets drain. In addition to that, there is a chance to occur infections. This first sort of DBS gadget isn't made to arrange for examinations on rodents since it gives a high danger of reactions for a little term of activity.

The second form of triggers has been portrayed 11,12 . The two gadgets are wearable triggers set contributes. It unravels two deformities of embedded frameworks: first, symptoms of medical procedure are characterized as anode addition just, and it isn't vital for the material to be bio-perfect since these types of devices are mounting on the body rather than keeping it inside. Another advantage is about the battery can change at any time depend upon the user's demand.

These trials are constrained from multiple points of view: subject must be put in isolated enclosures; despite the fact that they can detach their vest, and they hazard conceivable outcomes of harming the brain harm when the anodes are hauled out. The utilization of these wearable gadgets is likewise at one point excessively unsafe for long-haul experimentation, regardless of whether the two frameworks are considered to regard the electrical standards of tissues wellbeing.

The third kind of triggers is portrayed in ${ }^{13}$. These renditions of triggers are settled to the skull utilizing the dental glue while anodes are embedded into the cerebrum. The danger of contamination is constrained contrasted with the primary class of triggers.
When the mass volume of the device is considerably less, the subject has only less chance of damaging the gadget. In this setup, Since the battery is built in, the user cannot change the battery as he wishes.

These triggers were for one-sided incitements, a setup implied for 6-OHDA-instigated hemiparkinsonism. As neurodegenerative illnesses are respective, we built up a plan which licenses two-sided joining of terminals in the STN of both cerebral halves of the globe. For two-sided incitement, just a single incitement channel is required, yet the most extreme current must be multiplied ${ }^{14}$.

Regardless of the way that the sufficiency of Brain Stimulation has proved clinically, much more examination on brain networks controlled from Brain Stimulation is a major key. Thusly, rat appraisals about Brain Stimulation are required. The range values with different comparing results are needed to make a strong and successfully implantable DBS gadget ${ }^{4}$.

Many strategies are being used to learn and study about the Brain Incitement in which a big number of them used intense stimulations in the brain and another group checked about the long period incitement in the subjects. So the most important task is designing such a stimulator that can be accustom in all the testing environments in terms of size, precision, technology, power and safety ${ }^{6}$.

Generally, we can model a device in different ways. One way of modelling is using Application specified Type(ASIC), which has many positive points including size, technology, precision, safety, power and problems with these types are very expensive and this is meant for a particular purpose only. Apart from that, these units will be using energy harvester unit rather than using ordinary battery $\frac{15}{}$. Other way of modelling is assembling the custom components. It has the benefit of cheap and the same thing can be used again for different purposes. Comparing to the first model, this model requires more power ${ }^{16}$.

Moreover, these gadgets, for the most part, utilize inductive power exchange as opposed to a customary battery. This result in the advantage of less weight however with a disservice of short remote range. In correlation, 
remote triggers gathered from COTS modules are in generally speaking either too vast for use with zero sized subjects, or they require more power than what a regular battery can give ${ }^{2,10-13}$.

\section{Materials and Methods}

\subsection{Overall Design}

The unit framework includes circuit modules of the generator controlled by the source, correspondence and interfacing units, the programming unit and terminals. Heart of heartbeat generator is a chip with the correspondence modules. Pulses are exchanged to the cerebrum by means of cathodes. Figure 1 demonstrates the square graph of a general trigger framework and their interconnections.

\subsection{Microstimulator}

The Microcontroller that we are utilizing in this study is NRF51822 from Nordic Semiconductors that offers low vitality Bluetooth and $2.4 \mathrm{GHz}$ remote SoC. 32 -bit ARM

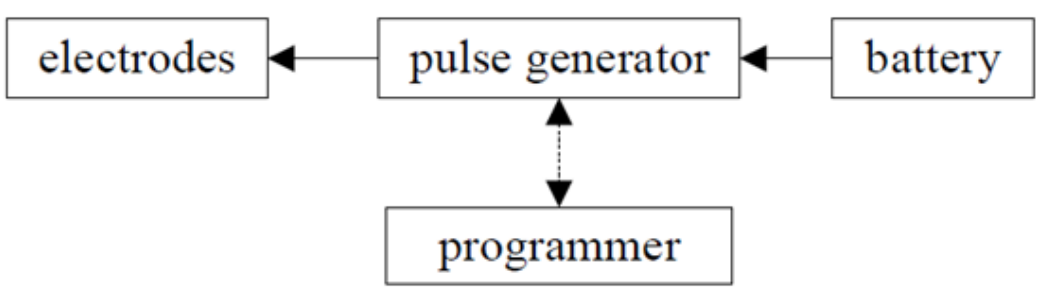

Figure 1. Block Diagram of a stimulator.

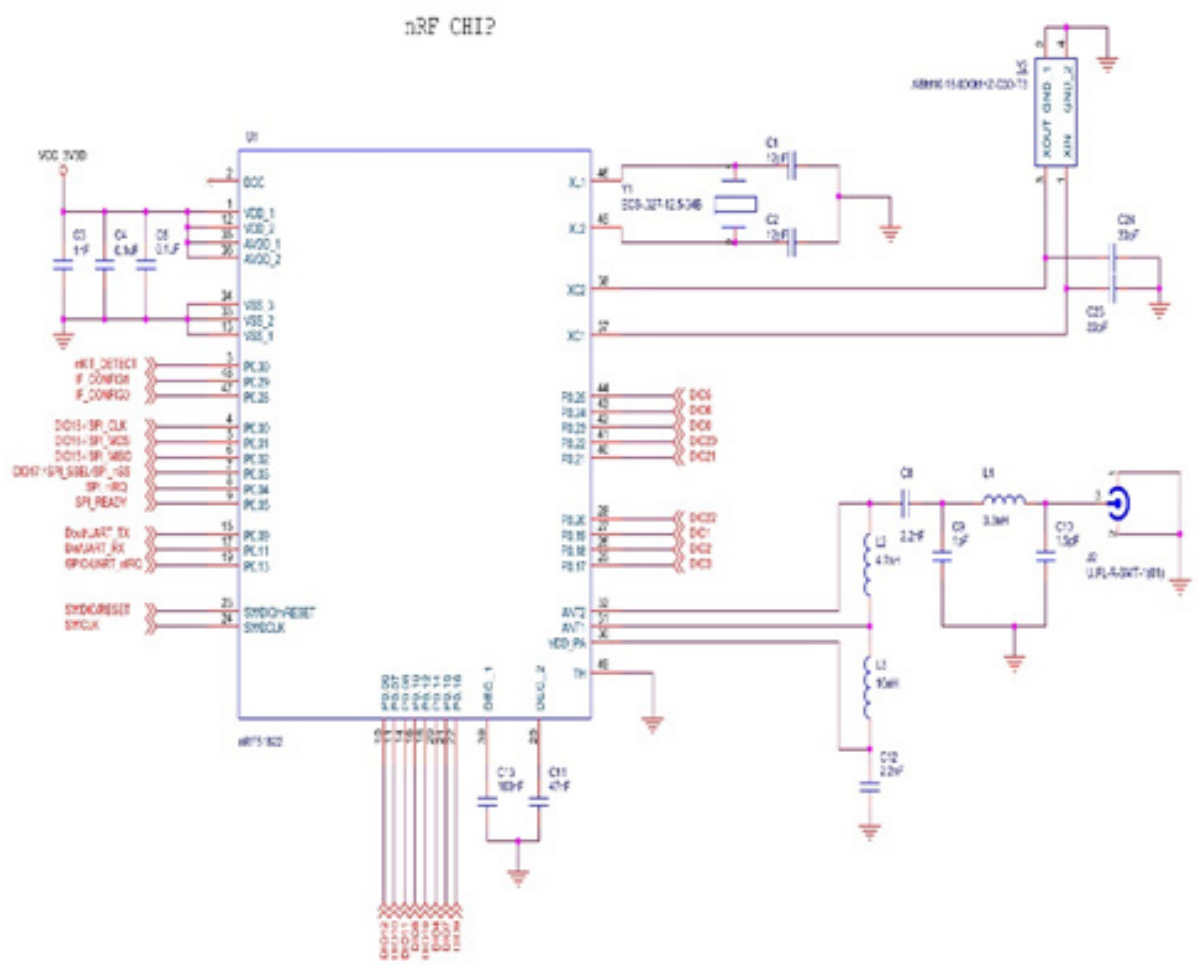

Figure 2. Schematics of NRF518122. 

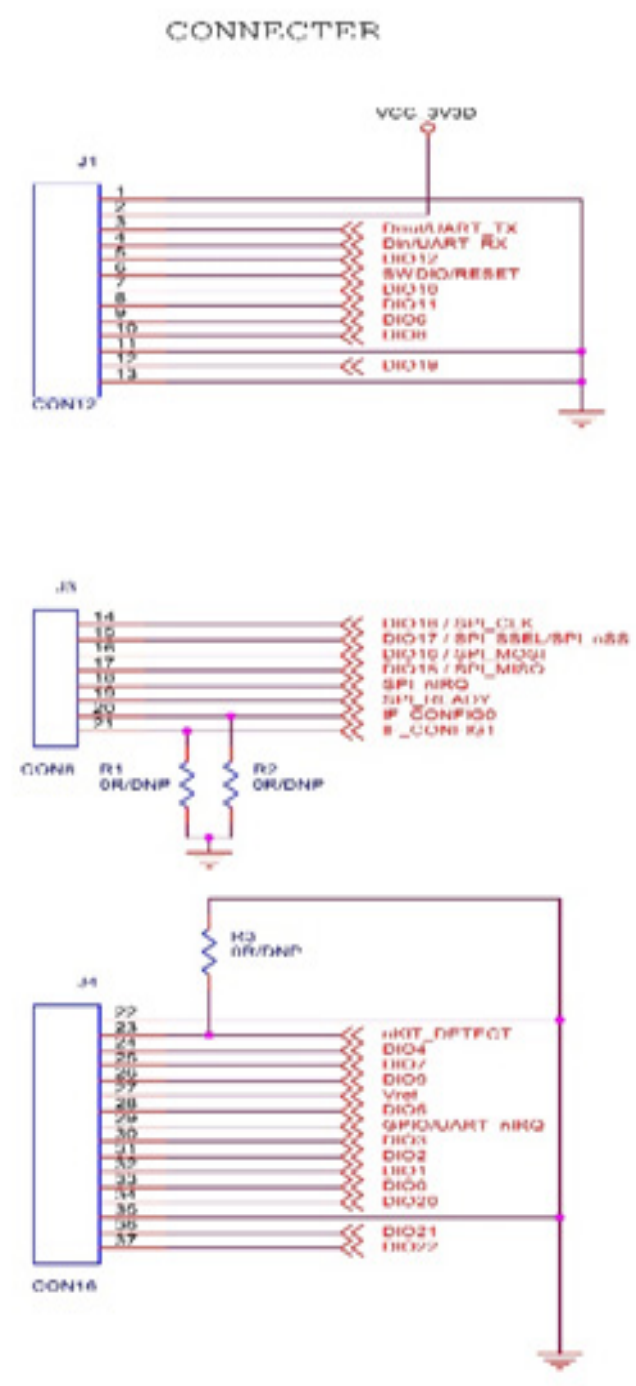

Figure 3. Schematics of Connectors.

Cortex CPU is having 256kb flash memory and $16 \mathrm{~kb}$ RAM is utilized in this framework. A 31 pin General Pin Input Output settings that permit interfaces, Pulse Width Modulation and quadrature demodulator to be mapped to any gadget. It has the benefit of configuration flexibly associated with the pinout terminal. It underpins both Bluetooth low powered convention stack and $2.4 \mathrm{GHz}$ convention stacks. It required a solitary power supply, and it additionally gives the client the option of utilizing on-chip straight controllers having a supply scope of $1.8-3.6 \mathrm{~V}$, coordinate $1.8 \mathrm{v}$ mode and DC-DC buck converter requires a supply size of $2.1-3.6 \mathrm{~V} \frac{17-22}{\text {. }}$ Microstimulator is fuelled up by one-coin estimate battery that is sufficiently brilliant to withstand for three months.

Schematic, Figure 1 describes the pin outputs, source points, General Input/Output Pins. Figure 2 illustrates all the jumpers and connectors that we are using in this system. Facility to program the microstimulator using Debugger is shown in Figure 3. We have also added 


$$
\text { J-TAG }
$$

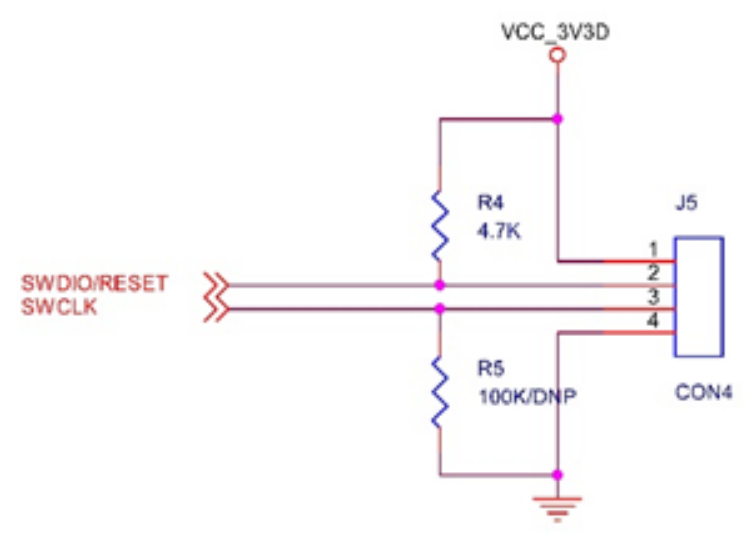

Figure 4. Schematics of Jtag (Debug).

the feature to facilitate Near Field Communication (NFC). Provision of Debugging is featured in Figure 4 as Jtag.

\subsection{The Transmitter and Receiver Design}

Transmitter System composed about Laptop/Mobile connected via USB to Base Station. The transmitter is

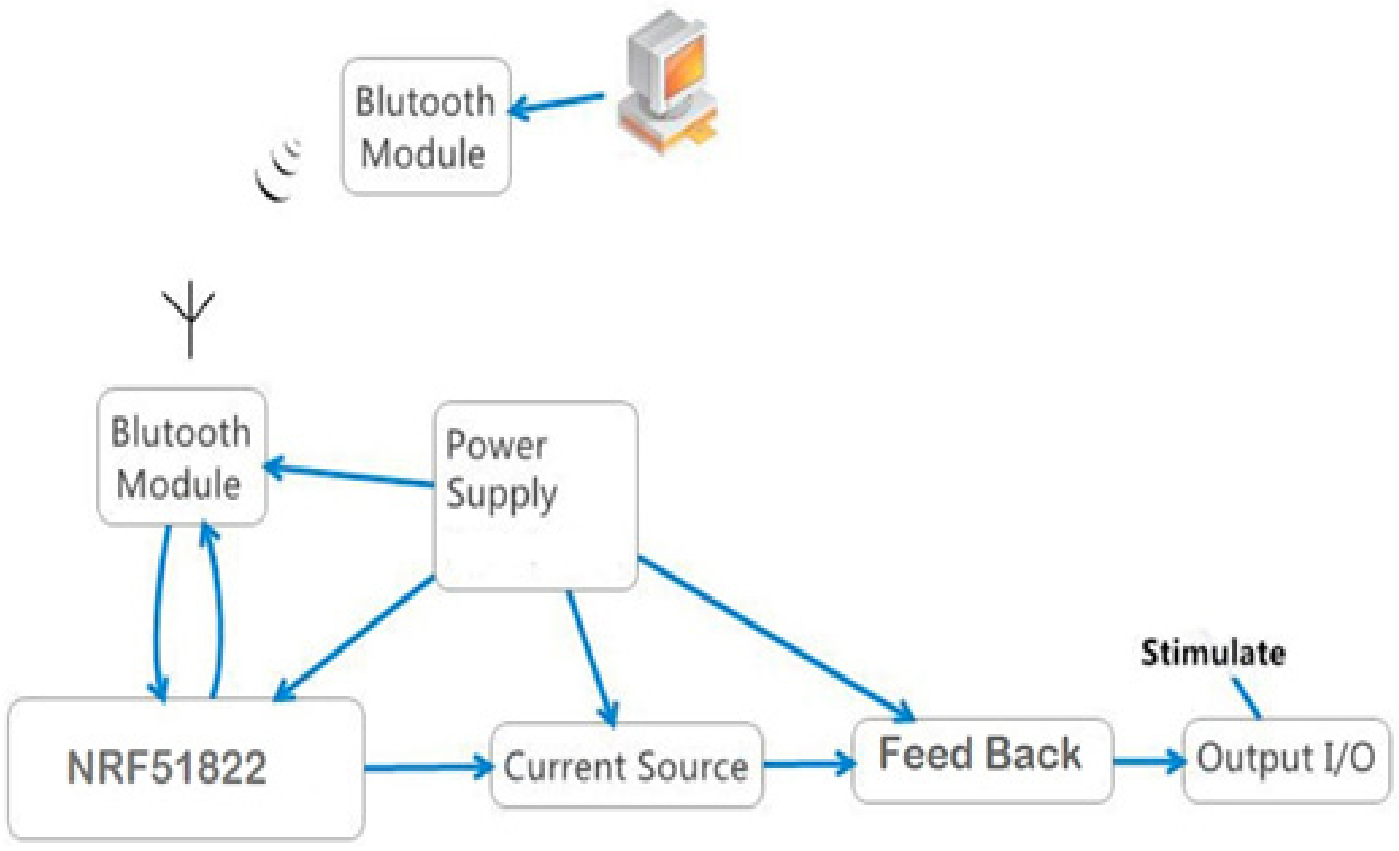

Figure 5. Transmitter and Receiver Design. 


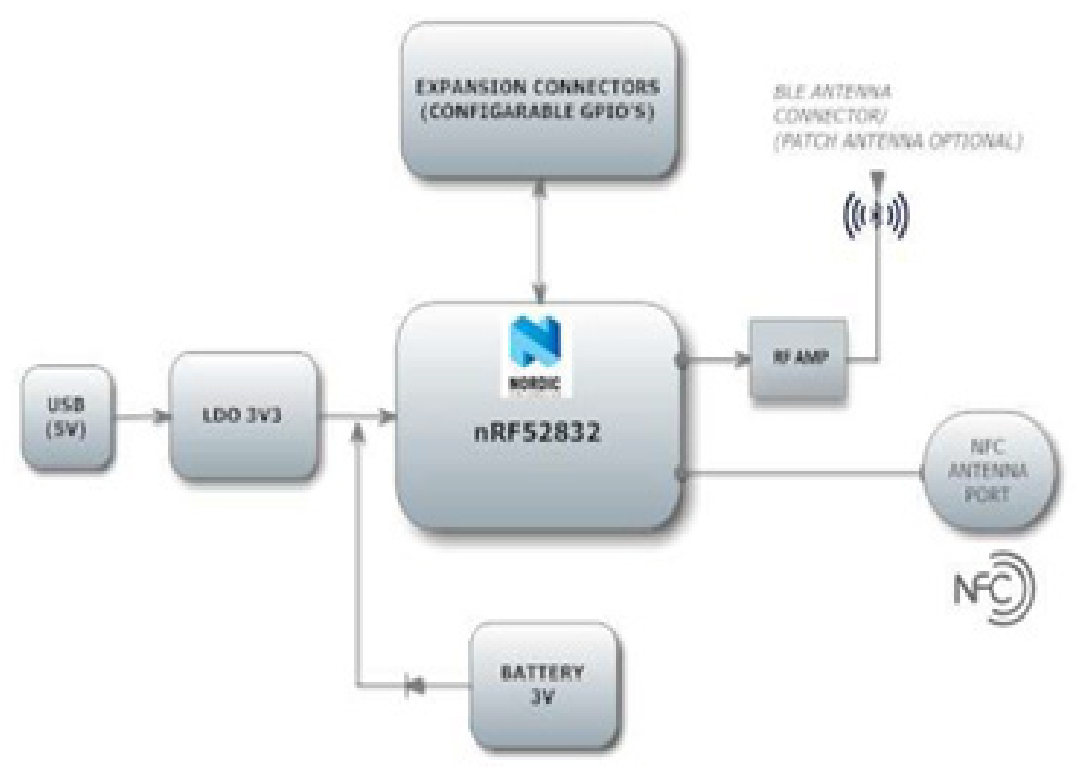

Figure 6. Block Diagram of Base Station.

added with Bluetooth module for the communication with Microstimulator. Base Station is built with Blue Bee module. Base Station can be activated either via USB from Laptop/Mobile or using coin size battery. Pictorial Representation of Transmitter and Receiver design and their interconnection is shown in Figure 5. Once it is activated, it will automatically paired up with the microstimulator. A complete block level representation of the base station is given in Figure 6.

Receiver System is clubbed with Microstimulator Unit enabled with Bluetooth Receiver. Base Station controls the power consumption of the Reciever System. Self-Explanatory Block Diagram describes the working of both units.

\subsection{Designing and Programming}

Schematics of this System are designed using Allegro PCB Design and OrCAD. The double layer PCB that we are using giving the advantage of minimum sizing and compact arrangement. The system is debugged using Jtag facility, and it is programmed in C language under Keil Platform.

To interface Base Station and Microstimulator, we are using Hercules software that can be installed either in Laptop or Mobile. The command to Microstimulator is activated using Hercules software. Screenshot of the software before triggering the pulses is shown in Figure 7.

\subsection{Waveform}

In this study, we e deliver programmable cathodic/anodic monophasic waveform. From the base station, we can control all the parameters of the waveforms. The controlled waveform can be further programmed by using digital resistors. Pulse amplitude, Pulse Width, Intertrain Delay and Number of Stimuli can be controlled from the base station. Although the system is delivering monophasic pulses, for the tissue safety and electrodes, it is always better to use unbalanced biphasic waves.

\subsection{Dimension}

One of the most important factors in the wireless telemetry is its size and weight of the microstimulator. If the size is too big, it will affect the rodent's behaviour and the performance. In this study, we are presenting a microstimulator with the dimension of $25^{\star} 13^{\star} 3$ millimetres, and it weighs 8.5 grams including battery. Figure 8 Shows the external dimensions of the stimulator. 


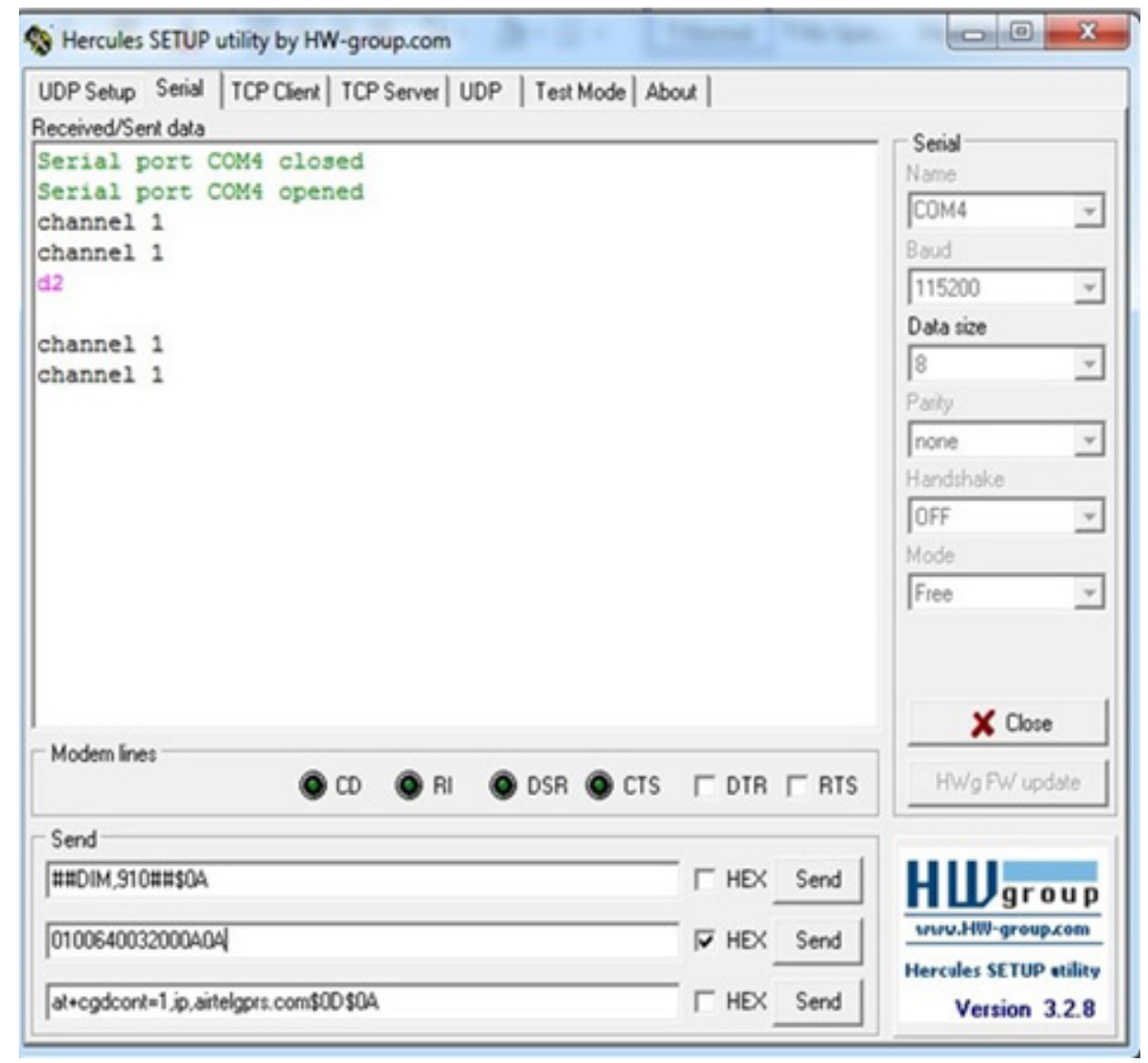

Figure 7. Programming Unit of the Stimulator.

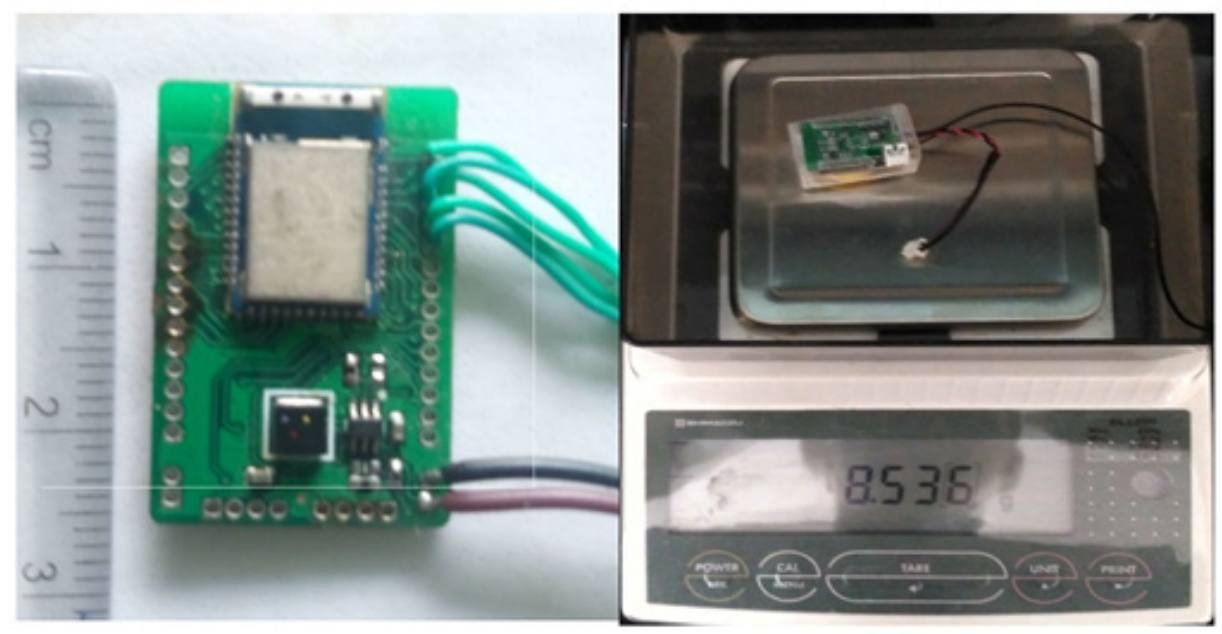

Figure 8. Physical Dimensions of the Stimulator.

\subsection{Cost Factor}

Here we are giving the complete cost estimation of the components of Stimulator unit in Table 1. As we men- tioned, stimulators commercially available now are highly expensive and they all lack appropriate technology to work efficiently. 
Table 1. Cost Estimation in US\$

\begin{tabular}{|c|c|c|c|c|}
\hline Quantity & Reference & Part & Unit Price & One board Cost \\
\hline 1 & C5(capacitor) & $120 \mathrm{PF} / 16 \mathrm{~V}$ & 0.014 & 0.014 \\
\hline 2 & C6,C9(capacitor) & $0.1 \mathrm{uF}$ & 0.0069 & 0.014 \\
\hline 2 & C7,C8(capacitor) & $12 \mathrm{pF} / 16 \mathrm{~V}$ & 0.014 & 0.028 \\
\hline 4 & $\begin{array}{l}\text { C10,C11,C12,C13 } \\
\text { (capacitor) }\end{array}$ & $1 \mathrm{uF}$ & 0.0069 & 0.028 \\
\hline 2 & C14,C15(capacitor) & $10 \mathrm{uF}$ & 0.014 & 0.028 \\
\hline 1 & $\begin{array}{c}\text { D1(Surface Mount } \\
\text { Device) }\end{array}$ & SMLP36RGB1W3 & 0.35 & 0.35 \\
\hline 2 & J1,J4(connectors) & CON2 & 0.069 & 0.069 \\
\hline 2 & J2,J3 (connectors) & CON14 & 0.35 & 0.69 \\
\hline 2 & J5,J6 (connectors) & CON4 & 0.11 & 0.22 \\
\hline 1 & L2(Inductor) & $10 \mathrm{uH}$ & 0.028 & 0.028 \\
\hline 1 & L3(Inductor) & $15 \mathrm{nH}$ & 0.028 & 0.028 \\
\hline 1 & L4(Inductor) & EPL3015-472MLB & 0.028 & 0.028 \\
\hline 3 & Q1,Q2,Q3(MOSFET) & 2N7002 & 0.21 & 0.62 \\
\hline 1 & R3(Resistor) & 0R/DNP & 0.0069 & 0.0069 \\
\hline 2 & R4,R5(Resistor) & $100 \mathrm{~K}$ & 0.0069 & 0.014 \\
\hline 1 & R6(Resistor) & $4 \mathrm{~K} 7$ & 0.0069 & 0.0069 \\
\hline 6 & $\begin{array}{c}\text { R7,R8,R9,R15,R16,R17 } \\
\text { (Resistor) }\end{array}$ & $2.2 \mathrm{~K}$ & 0.0069 & 0.041 \\
\hline 5 & $\begin{array}{c}\text { R10,R11,R12,R13,R14 } \\
\text { (Resistor) }\end{array}$ & $10 \mathrm{~K}$ & 0.0069 & 0.035 \\
\hline 1 & R56(Resistor) & $1 \mathrm{M}$ & 0.0069 & 0.0069 \\
\hline 1 & R57(Resistor) & $178 \mathrm{~K}$ & 0.0069 & 0.0069 \\
\hline
\end{tabular}


Table 1 Continued

\begin{tabular}{|c|c|c|c|c|}
\hline 1 & SW1(switch) & B3U-1000P & 0.41 & 0.41 \\
\hline 1 & U2(processor) & $\begin{array}{c}\text { MDBT42( NRF52 } \\
\text { Module) }\end{array}$ & 7.60 & 7.60 \\
\hline $\mathbf{1}$ & $\begin{array}{c}\text { U5(Switching } \\
\text { Regulator) }\end{array}$ & TPS61220DCKR & 0.76 & 0.69 \\
\hline $\mathbf{1}$ & Y1(crystal oscillator) & ECS-.327-12.5-34B & 0.69 & 5.53 \\
\hline 1 & & PCB & 5.53 & 4.15 \\
\hline
\end{tabular}

\section{Comparison}

Here we are comparing different types of the stimulator with various factors is observed in Table 2 . It is clear that the stimulator that we developed is dominant in many factors.

\section{Results}

\subsection{In vitro}

The output of the stimulator is connected to the electrode, and it dipped in $10 \%$ concentration of $\mathrm{NaCl}$. In order to

Table 2. Comparison between different stimulators

\begin{tabular}{|c|c|c|c|c|c|}
\hline $\begin{array}{c}\text { Reference } \\
\text { Paper }\end{array}$ & Size & Battery & Weight & Term & $\begin{array}{c}\text { Controlling } \\
\text { Parameters }\end{array}$ \\
\hline$[18]$ & $20 \mathrm{~mm}$ Diameter & $200 \mathrm{mAh}-3 \mathrm{~V}$ & Not Available & Not Available & $\begin{array}{c}\text { Current, Pulse width, } \\
\text { Delay, Frequency }\end{array}$ \\
\hline$[10]$ & $8 \mathrm{~mm}^{*} 30 \mathrm{~mm}$ & $4.60 \mathrm{~V}$ & 2.1 grams & 600 minutes & $\begin{array}{c}\text { Current, Pulse width, } \\
\text { Delay, Frequency }\end{array}$ \\
\hline$[19]$ & $15 \mathrm{~mm}{ }^{*} 28 \mathrm{~mm}$ & $36 \mathrm{mAh}-6 \mathrm{~V}$ & 7.4 grams & $\begin{array}{c}10,080 \\
\text { minutes }\end{array}$ & $\begin{array}{c}\text { Current, Pulse width, } \\
\text { Delay, Frequency }\end{array}$ \\
\hline$[7]$ & $25 \mathrm{~mm}$ Diameter & $280 \mathrm{mAh}-3 \mathrm{~V}$ & $7.8 \mathrm{grams}$ & $\begin{array}{c}12,960 \\
\text { minutes }\end{array}$ & Fixed \\
\hline
\end{tabular}


Table 2 Continued

\begin{tabular}{|c|c|c|c|c|c|}
\hline$[20]$ & $15 \mathrm{~mm}^{*} 22 \mathrm{~mm}$ & $250 \mathrm{mAh}-3 \mathrm{~V}$ & $5.08 \mathrm{grams}$ & $\begin{array}{c}17,280 \\
\text { minutes }\end{array}$ & $\begin{array}{c}\text { Current, Pulse width, } \\
\text { Delay, Frequency }\end{array}$ \\
\hline$[21]$ & $33 \mathrm{~mm}^{*} 20 \mathrm{~mm}$ & $250 \mathrm{mAh}-3.6 \mathrm{~V}$ & $11.5 \mathrm{grams}$ & $\begin{array}{c}14,400 \\
\text { minutes }\end{array}$ & $\begin{array}{c}\text { Current, Pulse width, } \\
\text { Delay, Frequency }\end{array}$ \\
\hline$[22]$ & $15 \mathrm{~mm}^{*} 18 \mathrm{~mm}$ & $250 \mathrm{mAh}-3 \mathrm{~V}$ & $4.75 \mathrm{grams}$ & $\begin{array}{c}31,680 \\
\text { minutes }\end{array}$ & $\begin{array}{c}\text { Current, Pulse width, } \\
\text { Delay, Frequency }\end{array}$ \\
\hline This Paper & $13 \mathrm{~mm}^{*} 25 \mathrm{~mm}$ & $3 \mathrm{~V} / 1000 \mathrm{mAh}$ & $8.4 \mathrm{grams}$ & $\begin{array}{c}1,29,600 \\
\text { minutes }\end{array}$ & $\begin{array}{c}\text { Current, Pulse width, } \\
\text { Delay, Frequency }\end{array}$ \\
\hline
\end{tabular}

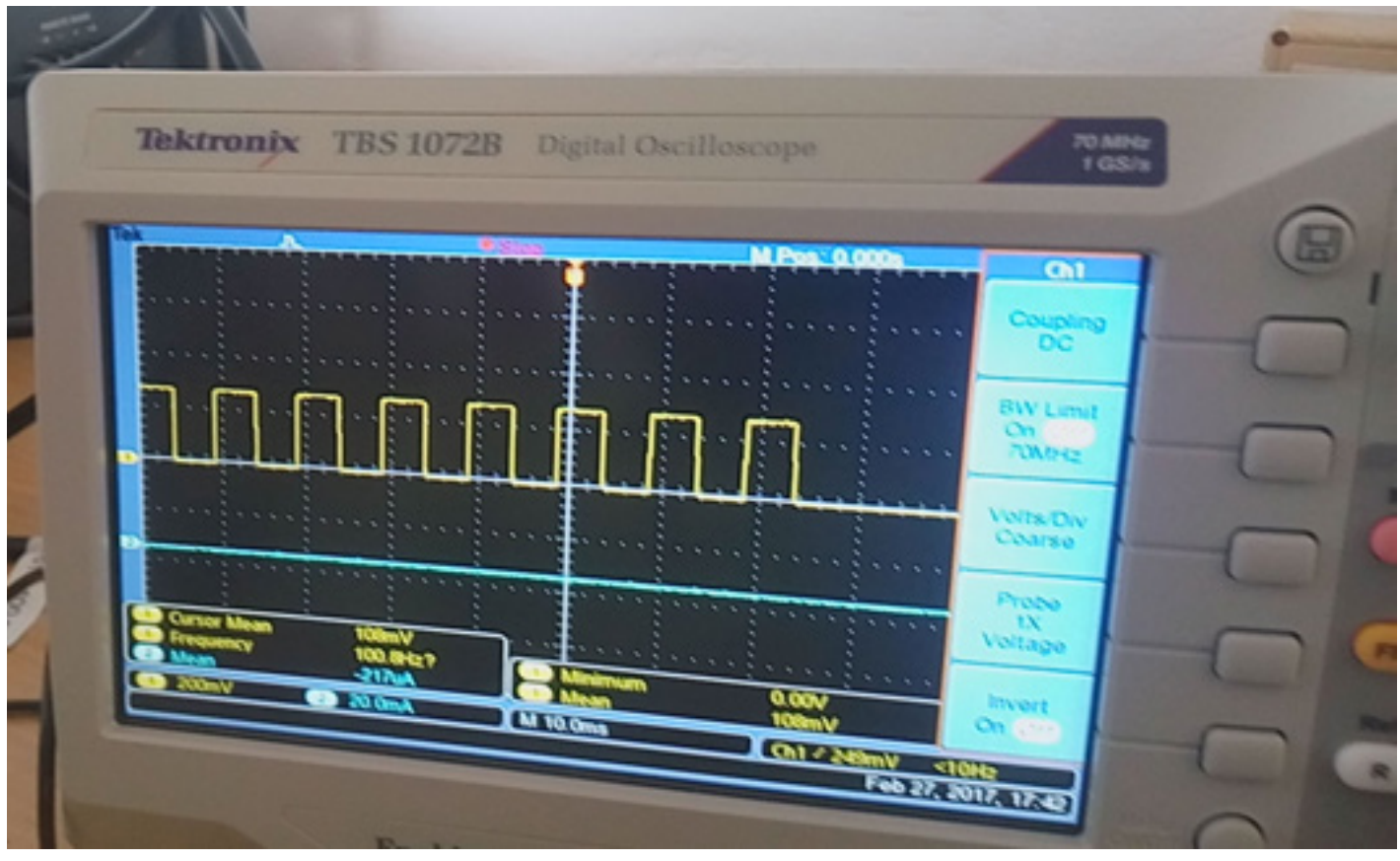

Figure 9. The output of the Stimulator.

check the output consistency, probes were connected to electrodes and checked the output. It is clear from the oscilloscope that the precise amount of pulses is delivered to the electrodes. Since we are using an extended lasting battery, the stimulator can be used with a minimum period of two months. We checked the output of the Stimulator using an Oscilloscope (Tetronics) is shown in the Figure 9.

\section{Discussion and Conclusions}

In this Paper, a new reusable portable microstimulator has been described in detail. This smart device can be 
used for a long-term experiment for studying neurophysiology of Rodents. Less power dissipation with advance microcontroller gives many possibilities to make this device smarter. Complete schematic is described in this paper provides reliable information about our work. The device can easily have paired up with base station once it turned on. Base Station will be providing all the required commands to the microstimulation according to the user Demands. Easily configurable and less complicate the user a better interface.

The most important advantage that we would like to highlight in comparison with other similar devices is long-term usability and sleek design that enables to adapt different experiment for the rodents. The Device can be improved by delivering Charge imbalanced biphasic waves and the battery life can be further improved using power harvesting system ${ }^{23,24}$. In conclusion, the newly designed product can be used in the stimulation studies in animal models.

\section{References}

1. Nowak K, Mix E, Gimsa J, Strauss U, Sriperumbudur KK, Benecke R, Gimsa U. Optimizing a rodent model of Parkinson's disease for exploring the effects and mechanisms of deep brain stimulation. Parkinson's Disease. 2011; p. 414-682. https://doi.org/10.4061/2011/414682.

2. Fluri F, Mutzel T, Schuhmann MK, Krstic M, Endres H, Volkmann J. Development of a head-mounted wireless microstimulator for deep brain stimulation in rats. Journal of Neuroscience Methods. 2017; 291:249-56. https://doi. org/10.1016/j.jneumeth.2017.08.024. PMid:28842194.

3. Cheung KC. Implantable microscale neural interfaces. Biomedical Microdevices. 2007; 9(6):923-38. https://doi. org/10.1007/s10544-006-9045-z. PMid:17252207.

4. Qian X, Hao H, Ma B, Wen X, Li L. Study on Dbs Device for Small Animals. Annual International Conference of the IEEE Engineering in Medicine and Biology Society. 2011; p. 6773-6.

5. Zhang D, Dong Y, Li M, Wang H. A Radio-Telemetry System for Navigation and Recording Neuronal Activity in Free-Roaming Rats. Journal of Bionic Engineering. 2012; 9(4):402-10. https://doi.org/10.1016/S16726529(11)60137-6.

6. Acosta AI, Noor MS, Kiss ZHT, Murari K. A Lightweight Discrete Biphasic Current Stimulator for Rodent Deep Brain Stimulation. IEEE Biomedical Circuits and
Systems Conference (BioCAS). 2015; p. 1-4. https:// doi.org/10.1109/BioCAS.2015.7348360. PMCid: PMC4924621.

7. Wu Y. Advances in computer, communication, control and automation: A Head Mountable Deep Brain Stimulation Device for Laboratory Animals. 2011; p. 275-80.

8. Duncan GH, Bushnell MC, Marchand S. Deep Brain Stimulation: a review of basic research and clinical studies. Pain. 1991; p. 49-59. https://doi. org/10.1016/0304-3959(91)90164-S.

9. Carlezon WA, Chartoff EH. Intracranial self-stimulation (ICSS) in rodents to study the neurobiology of motivation. Nature Protocols. 2007; 2(11):2987-95. https://doi. org/10.1038/nprot.2007.441. PMid:18007634.

10. deHaas R, Struikmans R, van der Plasse G, van Kerkhof L, Brakkee JH, Kas MJH, Westenberg HGM. Wireless implantable micro-stimulation device for high frequency bilateral deep brain stimulation in freely moving mice. Journal of Neuroscience Methods. 2012; 209(1):113-9. https://doi. org/10.1016/j.jneumeth.2012.05.028. PMid:22677175.

11. Alam M, Chen X, Fernandez E. A low-cost multichannel wireless neural stimulation system for freely roaming animals. Journal of Neural Engineering. 2013; 10(6):1066. https://doi.org/10.1088/1741-2560/10/6/066010. PMid:24162159.

12. A programmable closed-loop recording and stimulating wireless system for behaving small laboratory animals. Available from: https://www.nature.com/articles/ srep05963. Date accessed: 06/08/2014.

13. Pinnell RC, Dempster J, Pratt J. Miniature wireless recording and stimulation system for rodent behavioural testing. Journal of Neural Engineering. 2015; 12(6):1566. https://doi.org/10.1088/1741-2560/12/6/066015. PMid:26468659.

14. Kolbl F, Gilles NK, Frederic N, Florent B, Emilie F, Sylvie R, Abdelhamid B, Noelle L. An Embedded Deep Brain Stimulator for Biphasic Chronic Experiments in Freely Moving Rodents. IEEE Transactions on Biomedical Circuits and Systems. 2016; 10(1):72-84. https://doi.org/10.1109/ TBCAS.2014.2368788. PMid:25546861.

15. Rhew HG, Jachun J, Fredenburg JA, Dodani S, Patil PG, Flynn MP. A Fully Self - Contained Logarithmic Closed - Loop Deep Brain Stimulation SoC With Wireless Telemetry and Wireless Power Management. IEEE Journal of Solid-State Circuits. 2014; 49(10):2213-27. https://doi. org/10.1109/JSSC.2014.2346779.

16. CarboniC, Bisoni L, Carta N, Puddu R, Raspopovic S, Navarro X, Raffo L, Barbaro M. An integrated interface for peripheral neural system recording and stimulation: system design, electrical tests and in-vivo results. Biomedical 
Microdevices. 2016; 18(2):1-35. https://doi.org/10.1007/ s10544-016-0043-5. PMid:27007860.

17. Nordic Semiconductor. Available from: https://www.nordicsemi.com/. Date accessed: 2014.

18. Liu HY, Jin J, Tang JS, Sun WX, Jia H, Yang XP, Cui JM, Wang CG. Chronic deep brain stimulation in the rat nucleus accumbens and its effect on morphine reinforcement. Addiction Biology. 2008; 13(1):40-6. https://doi. org/10.1111/j.1369-1600.2007.00088.x. PMid:18269379.

19. Forni C, Mainard O, Melon DGC, Kerkerian-Le Goff L, Salin P. Portable microstimulator for chronic deep brain stimulation in freely moving rat. Journal of Neuroscience Methods. 2012; 209:50-7. https://doi.org/10.1016/j.jneumeth.2012.05.027. PMid:22659685.

20. Kouzani AZ, Abulseoud OA, Tye SJ, Hosain MDK, Berk M. A Low Power Micro Deep Brain Stimulation Device for Murine Preclinical Research. IEEE Journal of Translational Engineering in Health and Medicine. 2013; 2:15-109. https://doi.org/10.1109/JTEHM.2013.2264093.

21. Ewing SG, Porr B, Riddell J, Winter C, Grace AA. SaBer DBS: A fully programmable, rechargeable, bilat- eral, charge-balanced preclinical microstimulator for long-term neural stimulation. Journal of Neuroscience Methods. 2013; 213:228-35. https://doi.org/10.1016/j.jneumeth.2012.12.008. PMid:23305773 PMCid:PMC3574185.

22. Berk M, Kale RP, Kouzani AZ, Tye SJ, Walder K, ZarateGarza PP. Validation of a Portable Low-Power Deep Brain Stimulation Device Through Anxiolytic Effects in a Laboratory Rat Model. IEEE Transactions on Neural Systems and Rehabilitation Engineering. 2017; 25(9):136574. https://doi.org/10.1109/TNSRE.2016.2628760. PMid:28113945.

23. Beker L, Benet A, Meybodi AT, Eovino B, Pisano AP, Lin L. Energy harvesting from cerebrospinal fluid pressure fluctuations for self-powered neural implants. Biomedical Microdevices. 2017; 19(2):1-32. https://doi.org/10.1007/ s10544-017-0176-1. PMid:28425028.

24. Sikder MKU, Fallon J, Shivdasani MN, Ganesan K, Seligman P, Garrett DJ. Wireless induction coils embedded in diamond for power transfer in medical implants. Biomedical Microdevices. 2017; 19(4):1-79. https://doi.org/10.1007/ s10544-017-0220-1. PMid:28844084 